This is a peer-reviewed, accepted author manuscript of the following article: Ferreira, H., Kirk, D., \& Drigo, A. J. (2020). Pedagogical practices in health promotion: health-related bodily practices for adults and older people. Physical Education and Sport Pedagogy . https://doi.org/10.1080/17408989.2020.1800620

Pedagogical practices in health promotion: health-related bodily practices for adults and older people

Heidi Jancer Ferreira ${ }^{\mathrm{a}, \mathrm{b} *}$, David Kirk ${ }^{\mathrm{c}}$ and Alexandre Janotta Drigo ${ }^{\mathrm{a}}$

${ }^{a}$ Post-graduate program in Movement Sciences, São Paulo State University, Rio Claro, Brazil; ${ }^{b}$ Federal Institute of Education, Science and Technology of South of Minas Gerais (IFSULDEMINAS), Poços de Caldas, Brazil, ${ }^{c}$ University of Strathclyde, Glasgow, United Kingdom and University of Queensland, Australia

*Corresponding author

Heidi Jancer Ferreira

300 Dirce Pereira Rosa Avenue

Poços de Caldas, Minas Gerais, Brazil

37713-100

Email: heidi.ferreira@ifsuldeminas.edu.br

ORCID: https://orcid.org/0000-0002-8450-0197 


\section{Pedagogical practices in health promotion: health-related bodily practices for adults and older people}

Background: It is well established in the literature how exercise prevents chronic diseases. Nevertheless, we still lack knowledge about the ways in which healthrelated bodily practices might contribute to health promotion. Less is known about pedagogies in public health directed at adult and older-age groups, within non-formal educational settings. Considering a lack of tailored and attractive approaches to health-related bodily practices for adults and older people (Pettigrew et al. 2019; Dicky et al. 2017), we argue that there is a need to explore pedagogical practices that might further health promotion with this target group. Purpose: Drawing on Antonovsky's theory of salutogenesis (1996), the purpose of the study was to investigate how health and physical education (HPE) professionals delivered health-related bodily practices for adults and older people in community-based programmes.

Data collection and analysis: A qualitative and grounded theory study design was employed. Participants included six HPE professionals, three health centre coordinators and 34 adults and older people enrolled in four community-based programmes from Brazil. Condensed fieldwork was adopted to generate data through three-days visits to each programme. Multiple data sources comprised semi-structured interviews, non-participant observation of health-related bodily practices sessions and documents/materials produced by participants. Data was analysed through open, axial and selective coding, using the constant comparative method (Charmaz 2006).

Findings: Three themes were generated to explain the ways HPE professionals worked with adults and older people in health promotion: adopting a holistic 
view of health, serving as a health resource and nurturing further health resources. These practices included caring attitudes, such as listening carefully to adults and older people, showing attentiveness and responsiveness to them. Moreover, a key finding indicated that the HPE professionals served in their pedagogical practices as health resources, which the adults and older people learned to draw on to cope with life situations and experience health development.

Conclusion: The HPE professionals in the four programmes demonstrated to be capable of moving beyond a solely biomedical approach to health and focusing on the salutary factors that enable health promotion through the development of a combination of pedagogical practices that were consistent with salutogenesis.

Keywords: health education; exercise; salutogenesis; older adults; healthy ageing. 


\section{Introduction}

It has been argued that work practices of physical education teachers, coaches, and health and physical education professionals $\left(\mathrm{HPE}^{1}\right)$ have a contribution to make in public health (Lyon, Neville, and Armour 2017; Armour and Harris 2013; Pühse et al. 2011). Major expectations are based on a biological conception that 'exercise is medicine' (Sallis 2009; Taylor 2014) and on epidemiological evidence that physical inactivity constitutes a risk factor for non-communicable diseases (e.g. diabetes, obesity, metabolic syndrome) (Lee et al. 2012). However, this association between physical activity and disease prevention is limited to a biophysical focus (through for example an emphasis on Moderate to Vigorous Physical Activity), which in turn risks neglecting some of the social and cultural issues surrounding people's lives and their ways of being active (Kirk 2006).

A critical analysis of health-related physical activity provided by Piggin (2019) indicated that the dominant definition of physical activity is often narrow and reductionist since it prioritises biological aspects and does not cover other dimensions (e.g. intellectual, psychological, social, cultural, and others). The idea of physical activity is useful for enhancing physical and physiological health outcomes, but it is not enough to capture lived experiences, meanings and emotions of people who engage in it (Piggin 2019).

\footnotetext{
${ }^{1}$ The term Health and Physical Education (HPE) professionals is used to refer to health workers whose speciality is physical education (Bachelor and/or Teacher Education degree), whether they are teachers, instructors or others who work specifically with health-related bodily practices in public health settings, such as primary health care centres, community-based programmes and others.
} 
As an alternative, we adopt in this study a more holistic notion of health-related bodily practices, which refers to an expression of physical culture that involves a set of practices that are organised and constructed from people's knowledge and experiences of play, dance, sports, recreation, exercise, martial arts and gymnastics, within specific contexts (Brazil 2013). This idea converges with Piggin's $(2019,8)$ new definition of physical activity, which says that it involves 'people moving, acting and performing within culturally specific spaces and contexts, and influenced by a unique array of interests, emotions, ideas, instructions and relationships'. Health-related bodily practices convey a holistic and transdisciplinary way of thinking and working with health promotion that opens dialogue with other forms of knowledge such as Humanities and Social Sciences (besides Biological Sciences), and importantly, with other aspects of participants' lives, including their needs, interests and emotions (Alves and Carvalho 2010).

There is a recent concern with the development of pedagogies for health, mainly in school context for younger age-groups (Kirk 2020; McCuaig and Quennerstedt 2018; Quennerstedt 2008, 2019; Armour and Harris 2013; McCuaig, Quennerstedt, and Macdonald 2013; Haerens et al. 2011). Fewer studies have engaged in research in nonformal educational settings among people in older stages of life (Ericson et al. 2018; Mansfield and Rich 2013; Grant 2012; Jette and Vertinsky 2011). We argue that there is also a need to discuss pedagogical approaches for non-formal health educational settings involving older age-groups. The notion of pedagogy as the alignment among teachers/teaching, learners/learning and subject matter (Kirk 2013) can be useful for rethinking similar interactions that occur within the context of community-based programmes, that is, among HPE professionals' practices, adults and older people's health needs, and health-related bodily practices. 
In this context, the present study aimed to investigate how HPE professionals delivered health-related bodily practices for adults and older people in communitybased programmes. In particular, we sought to understand the practices developed by HPE professionals who were working in the field of health, within community-based programmes that were already in place. In order to investigate these practices of health promotion, the study drew on salutogenesis theory (Antonovsky 1979), which focuses on the origins of health, in contrast to a pathogenic orientation to the causes of disease.

\section{Antonovsky's theory of salutogenesis}

Recent studies have indicated that salutogenesis is a powerful theoretical framework to advance the understanding about health and physical education as a means of health promotion (Kirk 2020; McCuaig and Quennerstedt 2018; Quennerstedt 2008, 2019; McCuaig, Quennerstedt and Macdonald 2013). Antonovsky $(1979,1987)$ proposed salutogenesis as an alternative to the pathogenic perspective to health promotion. Instead of asking what are the causes of certain diseases, he suggested a focus on what are the origins of health and why people keep healthy. In this sense, salutogenesis can extend our knowledge about what ways of delivering health-related bodily practices can be related to adults and older people perceiving health development and continuing to be physically active.

According to the salutogenic model, nobody can be classified as totally ill or totally healthy (Antonovsky 1979). Antonovsky (1979) suggested that instead of poles, health can be seen as a process of moving within a continuum, where a person can be positioned in any point and move towards an 'ease' or 'dis-ease' side, according to life situations. To explain what helps people move towards the ease side of the health continuum, Antonovsky (1979) proposed the concepts of generalised resistance resources (GRRs) and the sense of coherence (SOC). GRRs or health resources 
(Quennerstedt 2008; McCuaig and Quennerstedt 2018) involve a set of characteristics of different types (e.g. cognitive, emotional, material, relational, cultural) that an individual has access to and can draw on to avoid or overcome stressors in everyday life (Antonovsky 1979). SOC is related to an individual's comprehension, motivation and confidence that challenging situations in everyday life can be handled. Thus, SOC has three components: meaningfulness, manageability and comprehensibility (Antonovsky 1987). In short, salutogenesis explains that when someone is confronted with stressors in daily life, the person can mobilise available and appropriate resources and, in so doing, become healthier (Antonovsky 1979).

\section{Methods}

Grounded theory (GT) research design was employed in the study. As Charmaz (2006, p.187) explains, it is 'a method of conducting qualitative research that focuses on creating conceptual frameworks or theories through building inductive analysis from the data'. Condensed fieldwork method (Stenhouse 1978) guided data generation along with the strategy of theoretical sampling (Charmaz 2006), which has a logic of sampling that seeks pertinent data for developing concepts in the study. Data analysis was conducted through open, axial and selective coding (Kolb 2012), using the constant comparative method (Charmaz 2006). GT involves a systematic and iterative process of data generation and analysis that develops a theoretical explanation about a particular research problem and empirical situation, which is defined as substantive theory (Charmaz 2006; Glaser and Strauss 2017). We engaged in GT to explain how the HPE professionals delivered health-related bodily practices for adults and older people in community-based programmes. We first generated a substantive theory grounded in data and then, in order to further develop and refine it, we conducted a process of theoretical integration with a formal theory, that is, the existing literature on the general 
and conceptual area of health promotion (Glaser and Strauss 2017). The literature on salutogenesis (Antonovsky 1979,1987, 1996) was employed since it specified general concepts to explain the process of health promotion that applies to different substantive areas (Glaser and Strauss 2017).

\section{Setting and participants}

The context of the study was non-formal health educational settings, in particular, community-based programmes that focused on the delivery of regular health-related bodily practices as means of health promotion, under the supervision of HPE professionals. The programmes took place in four communities in Brazil and they welcomed adults and older people from all backgrounds, medical conditions, abilities and mobility levels. The programmes were government sponsored and implemented under a public health policy that had a socio-critical perspective on health promotion and therefore prioritised actions for modifying social determinants of health and alternatives to overcome biomedical approaches to health that were disease-centred. The programmes' guidelines did not drive the HPE professionals to work with uniform approaches to health promotion, thus, they had autonomy to design their own methods. Moreover, other conditions may have supported the HPE professionals to develop their ways of working, including community accessibility (location adjacent to primary health care centres) and adequate time to strengthen connectedness due to programmes' long-term design, regular meetings and stable groups. The HPE professionals' approaches were grounded mostly in their experience (by trial and error), ability to meet participants' needs and emerging expectations, personal philosophies and programmes' policy (including principles such as social integration, continuous education, social justice and others). 
The programmes were selected by theoretical sampling (Charmaz 2006), using the notions of comprehensive health, salutogenesis and health-related bodily practices. The study involved four programmes that sought to develop alternative approaches to health promotion that were not limited to disease prevention and worked beyond the physical dimension, for example focusing on mental, social and/or emotional aspects of participants.

Programme 1 (P1) was created in 2012 within a community health centre. This programme was implemented following Brazilian health policies that intended to provide health services supported by multi-professional teams, comprised of physiotherapist, dietitian, social worker, psychologist, HPE professional, among others (Brazil 2008). The HPE professionals delivered group sessions of health-related bodily practices once or twice a week for communities within the health centre (in small rooms, using recyclable and adapted materials). The sessions focused on low-impact and chair-based exercise, yoga, stretching and dance.

Programmes 2 and 3 are examples of a public health strategy called 'Academia da saúde' (Health gym) (Brazil 2011). This strategy was supported by National Health Promotion Policy (Brazil 2014) and it was directed at the promotion of health-related bodily practices, leisure and care. Both programmes were implemented adjacent to community health centres, which facilitated participants' access to health services. In Programme 2 (P2), sessions were delivered daily and they were based on dance, fitness, low impact exercise and group conversations. In Programme 3 (P3), sessions were delivered twice or three times a week, based on recreational activities, group dynamics and low impact exercise.

Programme 4 (P4) was created in 2009 by a cross-sectorial partnership amongst Sports, Health and Social Inclusion departments of the Local Government. It took place 
in multiple sites of the city, such as community centres, gyms, open areas alongside the beach, mental health care and social services centres. Sessions were based on adapted sports for older people (volleyball and handball), dance, low-impact exercise, walking and recreational events.

Three stakeholders' groups participated in the study. The first group comprised six HPE professionals ( 3 females, 3 males, age 32-43y). One HPE professional had bachelor qualification in Physical Education, the other five HPE professionals held both bachelor and teacher education degree in Physical Education ${ }^{2}$. The HPE professionals' experience time in the community-based programmes ranged from three to nine years. The second group involved three health centre coordinators ( 3 females; age 30-51y) all qualified in Nursing. The third group consisted of thirty-four adults and older people (2 males, 32 females; age 30-80y), who attended the programmes regularly. In general, they joined the programmes motivated by an intention of improving physical health outcomes due to existing biophysical conditions (e.g. overweight, pain, illness). This latter group, which we identified as 'participants', was socioeconomically disadvantaged, that is, formed by people from lower income backgrounds and neighbourhoods. Moreover, they had limited access to educational opportunities due to poor literacy skills.

\section{Data generation}

${ }^{2}$ The HPE professionals acknowledged that their qualification was not enough to prepare them for the complex work in public health. According to them, there was a lack of knowledge from Humanities and Social Sciences to support them with a broader understanding about public health settings. 
Condensed fieldwork was employed for data generation since this method allows the researcher to conduct a multi-site study and to gain access to multiple data sources in a relatively short period of time (Stenhouse 1978). Data generation was conducted from July to November, 2018. The main researcher made a three-day visit to each programme in their natural setting, spending most time on interviewing, but also on observation of sessions and collection of documents and materials made by participants when available (e.g. photos, reports, forms, and others).

Data was generated from multiple sources: interviews with six HPE professionals (minimum of three sessions each); interviews with three health centre coordinators (a session each); nine group interviews with adults and older people, which were organised according to participants' availability and interest to join (P1- three sessions with ten participants; P2 - two sessions with sixteen participants; P3 - four sessions with eight participants; P4 - participants were not formally interviewed due to their lack of time availability and shyness); and, non-participant observation of thirtyfour sessions of health-related bodily practices.

Online meetings occurred with HPE professionals at two moments: prior to the visits, in order to discuss the schedules and research protocol; and after data analysis, with the purpose to present and discuss findings.

\section{Non-participant observation}

Non-participant observation was used to provide insights for interviews, check information given by participants and describe how sessions were conducted as means of health promotion. Fieldnotes comprised information focused on instructional aspects like climate and environment, session structure, content, types of activities, HPE professionals' behaviour and instructional strategies, time allocation, participants' 
behaviour and response to activities, relationship between HPE professionalparticipants, and participants-participants.

\section{Interviews}

Interviews were conducted as an extension of the observations, with an intention to capture participants' experiences (Stenhouse 1978). The interviews were semistructured, consisting of open-ended questions designed to allow HPE professionals to reflect on their beliefs, strategies and behaviours in relation to their practices; to guide adults and older people to elaborate on their experiences attending the community-based programme; and to let the health centre coordinators share their perceptions on the contribution of health-related bodily practices to the communities.

Interview guides were constructed following the salutogenic framework and the strategy 'health by stealth', as suggested by McCuaig and Quennerstedt (2018). The authors warned that the pathogenic paradigm is so dominant in Western societies that people, when asked about their health, probably would report about disease or expected behaviours of balanced diet, physically active lifestyle and so on. Then, they suggested to investigate the topic of health without employing the word 'health'. Instead, the interview guides used expressions like 'good life' or 'to live well'.

All interviews were carried out at the sites where the sessions occurred. The main researcher conducted the interviews, which lasted approximately 40 minutes each. The interviews were audio-recorded with participants' agreement and transcribed verbatim. The transcripts were sent to participants for validation.

\section{Data analysis}

Data was analysed through open, axial and selective coding, using the constant comparative method (Charmaz 2006; Kolb 2012). Comparisons were conducted horizontally and vertically across data sources (interviews, fieldnotes, documents), 
cases (four community-based programmes) and stakeholders' groups (HPE professionals, health centre coordinators, participants).

The analytical process involved several steps. Data were systematically examined through close and repetitive readings of transcribed interviews and fieldnotes, and broken into pieces. Data-with-data comparisons were conducted to find similarities and differences. We engaged in open coding to study fragments of data in detail and name them under labels. Initial codes were elaborated by gerunds because it helped thinking about actions and staying close to participants' experiences (Charmaz 2006). In the next step of axial coding, we conducted further constant comparisons across data and codes along with analytical questions to assemble pieces of data in different ways and develop the initial codes into themes, as elements of an emerging analytic frame. At this stage, we specified the dimensions of themes, relating subthemes to them. In the third step of selective coding, we selected the most significant themes, refined and established relationships among them, culminating with the development of a substantive theory, which explained what was happening in the particular situation of the sites we studied relating to the delivery of health-related bodily practices as part of a process of health promotion. We conducted several stages of data generation and analysis to develop a theoretical explanation that was grounded in data. In the final step, our findings (substantive theory) were brought into relation to the literature on salutogenesis and health promotion (formal theory). The procedure of theoretical integration between substantive and formal theory helped us further develop the themes, particularly in terms of filling gaps in our knowledge about the process of health promotion among adults and older-age groups.

The analysis focused on understanding HPE professionals' practices for working with adults and older people, as part of the process of health promotion. The literature 
on salutogenesis and health promotion along with analytical questions were applied as an orientation to explore the practices used by HPE professionals. Examples of questions included: How did HPE professionals enact a focus on health promotion? How did they relate to participants? How did their practices reinforce or develop health resources and the components of sense of coherence? These analytical questions guided researchers to code in line with the essence of salutogenesis (Mittelmark and Bauer 2016). The analysis was performed manually by two researchers, with the aid of the qualitative data analysis software QSR International's NVivo 12 for the purpose of data management.

\section{Findings}

Findings are reported in terms of HPE professionals' practices developed in their work with adults and older people: (1) adopting a holistic view of health; (2) serving as a health resource; and (3) nurturing further health resources.

\section{Adopting a holistic view of health: 'a human being as a whole'}

The HPE professionals in this study showed a holistic view of health, which means that they viewed participants as whole human beings who carry life stories rather than only physical bodies suffering from a condition or disease they may have. The HPE professionals considered in their way of working not only the biophysical conditions of participants, but also their emotions, experiences, family backgrounds, responsibilities, interests and needs. This perspective was described by a HPE professional:

BARBARA: When you have this way of looking within the area of health (...) You start to see a whole way of dealing with that person without being just the knee, glucose and overweight. (...) You see possibilities beyond what is being worked on, a human being as a whole, not only a human being and disease, not a 
human being and his/her body. But a human being with all the story and experiences he/she has. (...) the HPE professional's job isn't just to prescribe exercise, it isn't just to plan a training or to organise a session but a job that also deals with the emotional side of people. (HPE professional, age 43, P2)

This holistic understanding framed the goals of the HPE professionals' pedagogies for working with health-related bodily practices. The data suggest that the main aspiration of the HPE professionals' pedagogical practices was related to participants being able to experience and perceive health development in the physical, mental and social dimensions, thus, experiencing a better quality of life.

SUSAN: To focus on participants' mental, social and physical development, health promotion and prevention of diseases through a variety of activities. That is why it doesn't focus only on the physical aspect. Thus, people feel good and want to stay in the programme. (HPE professional, age 32, P3)

CHARLES: I thought this programme was very much about the physical part. (...) It's about bringing people here who were at home, who sometimes live alone, who sometimes don't have other occupation, don't have anything else to do due to a lack of choice. Here, they have contact with other people, who will invite them to travel together, to go for a tour, to play bingo on the weekend. Then, you re-insert them in a social life.

(HPE professional, age 39, P4)

Adopting a holistic view of health led the HPE professionals to not restrict their approaches to exercise prescription. In their pedagogies, they were also concerned with other aspects of participants' lives, and so they sought to gain in-depth knowledge about their family story, problems, emotions, preferences and psychological needs. The HPE 
professionals knew the life story of each person who attended their sessions, and this knowledge supported them to pursue their aspiration and to find ways to increase participants' motivation to continue engaged in health-related bodily practices. The HPE professionals commented on the importance of gaining in-depth knowledge about community's members to contribute in a way that really makes a difference in their lives.

BARBARA: (...) if you don't see how a community works, people who live there, how they live, what they do, what they need, what are their demands, you end up limited in a very little world and creating nothing. (HPE professional, age 43, P2)

Then, the HPE professionals drew upon their perceptive skills and attentive listening over a long period of contact with participants to know about social and emotional aspects of their lives. This temporal dimension of regularity and continuity in their contact with the participants seemed to be crucial to enable this process of getting to know each person deeply.

Overall, the findings suggest that by adopting a holistic view of health, the HPE professionals focused on whole persons rather than only the medical condition they may have, and gained in-depth knowledge about personal, social, and cultural factors surrounding participants' lives. Importantly, these practices enabled the HPE professionals to create bonds with the participants and develop another practice, which is related to establishing caring relationships with them.

\section{Serving as a health resource: 'a person who they can count on and trust'}

The HPE professionals served as a health resource in themselves, that is, in their pedagogical practices with adults and older people, which were based on establishing caring relationships. As we observed, the HPE professionals became a health resource 
for participants by showing attentiveness and responsiveness, which means that they listened to adults and older people carefully, with respect and genuine interest, in order to recognise their needs and respond to them. Hence, the participants perceived the HPE professional as a key person to support them socially and emotionally, which can be considered, in salutogenic terms, as a health resource.

The way the HPE professionals cared for the participants was through paying attention to their needs, interests and feelings, and demonstrating willingness to make a positive contribution to their lives. A HPE professional demonstrated awareness of what the participants were in need: 'they need someone to unburden themselves'. Our fieldnotes corroborate this, as we observed a behaviour pattern of the participants of getting close to the HPE professionals to have a conversation in the beginning or end of sessions. The identification and awareness of other's needs constitute part of caring. Another part is responding to what was identified. The way the HPE professionals responded to participants was by listening to them with patience.

CHARLES: They come to me to complain, they need someone to unburden themselves. And they see me a lot in this role, a person who they can count on and trust. (...) They tell a lot about family situations, they're bad, what happened at home... (...) What I do is to let them speak and listen to them (...) The point is that they use here as an escape valve. (HPE professional, age 39, P4)

The relationships with participants were based on trust, which probably encouraged them to look for the HPE professionals often to talk about personal issues. The data indicate that participants used the HPE professionals' caring behaviour to help them regulating emotions, strengthen themselves emotionally and handling tough situations, or in Charles' words, 'as an escape valve'. 
In fieldwork, we observed that the HPE professionals made time every session (approximately ten minutes) for having conversations and interacting regularly with participants as a strategy for listening to them. A HPE professional confirmed about her concern with checking about personal issues of participants, like about their mood in that day and following-up situations they were living, in order to demonstrate interest and attention to their daily lives. To illustrate, Susan (HPE professional) reported that she did not started sessions prescribing exercise. Instead, she began sessions with conversation.

SUSAN: I don't begin the class with exercise. (...) I always try to stimulate something of speech. I always ask several things to them. (...) Because I think it's very important, they know that someone is looking after them. (HPE professional, age $32, \mathrm{P} 3$ )

Similarly, after identifying participants' demands for talking and unburdening, another HPE professional proposed extra sessions for having group conversations about topics chosen spontaneously as a strategy to enable a group of middle-aged and older women to express themselves and being listened to by others. The participants recognised that having conversations with the HPE professionals and peers helped them to deal with problems. The HPE professionals' caring behaviour was perceived by them as a contribution to their lives.

GRACE: This group conversation that we do on Fridays, we tell our problems (...) Here, we tell, we unburden, we cry. (Participant, age 54, P2)

DOROTHY: She's not just our teacher, she's our friend, our counsellor. She's everything, you know? She is everything to us. (...) If she perceives that we are 
sad, she comes to talk, she wants to know what is happening. (Participant, age $66, \mathrm{P} 3)$

DIANA: (...) I say if it wasn't for her charisma and the attention she gives us, maybe there wouldn't be so many people here. (Participant, age 64, P2)

Perceiving HPE professionals' caring behaviour can be associated with participants developing attachment to HPE professionals and willingness to persist in the community-based programmes. In fieldwork, we observed that session climate was built upon a sense of warmth and affection. As participants arrived for the session, they greeted each other and the HPE professional with hugs, kisses, smiles and, they had conversations that sounded cheerful.

The findings showed that more than delivering health-related bodily practices, the HPE professionals cared for the participants in their relationships. They served as a health resource in themselves along with their caring behaviour with participants. The HPE professionals' attentiveness, support and responsiveness helped the participants to develop strategies for coping with life situations and find meaning in their bodily experiences. Therefore, the adults and older people were stimulated to develop the SOC components of meaningfulness and manageability (Antonovsky 1987).

\section{Nurturing further health resources: 'it's not just exercising'}

The HPE professionals also served as a means of the participants accessing further health resources, which they could draw upon to cope with problems and experience life positively. In their pedagogies, the HPE professionals delivered health-related bodily practices in a way that enabled participants to develop skills, knowledge and experiences that functioned as health resources. The health resources identified in the study included the development of physical fitness, social ties, social support, health- 
related knowledge, communication and emotional skills. So, the HPE professionals did not focus their work only on participants achieving physical health outcomes. The data provided evidence that they offered bodily experiences that stimulated participants' development in the physical, social, cognitive and emotional dimensions of health.

In the participants' views, the HPE professionals' pedagogies offered opportunities for them to be physically active as well to interact with others and develop life skills:

MARGARET: It isn't just the exercise that Susan works with us. She works on mentality, concentration and the friends that we make here. That's really good. (...) It is not just exercising. (Participant, age 46, P3)

KIMBERLY: Besides doing physical activity, we interact with our colleagues, we learn to be a better fellow, we learn to offer more support to others. (Participant, age 62, P3)

Regarding the physical dimension, the HPE professionals described they organised sessions of stretching, strengthening, conditioning and relaxation to attend participants' physical needs.

As a result, the participants perceived improvements in several components of physical fitness, such as cardiorespiratory endurance, muscle strength, flexibility, agility, balance and weight loss.

SHARON: I lost weight, now I do everything, I do ballroom dance all afternoon and I don't get tired.

PAUL: But a lot has changed. I was rusty. Now I can move my legs back and forth. 
(Sharon, age 55; Paul, age 70; P3)

These physical health outcomes became health resources for the participants in terms of pain relief, vitality and a sensation of a relaxed and functional body. Being able to do simple activities with ease gave a sense of manageability and meaningfulness to them (Antonovsky 1987).

In the social dimension, the HPE professionals organised recreational events mainly during special dates like Carnival, Easter, Christmas and others as a strategy to foster socialisation among participants. Photographic records of the events that were collected during fieldwork corroborate what the HPE professionals' reported:

MICHAEL: When it's a special date, we do a project for that date. For example, we did the elderly week in October (...) So, on commemorative dates we do a different activity. (HPE professional, age 40, P1)

ANNE: Depending on the date, we do a special dance or a play, or a walk, or something. (HPE professional, age 34, P1)

Moreover, we identified that HPE professionals prioritised a diversification of activities as a strategy to facilitate participants' experiences of enjoyment and fun, including ball games, recreation and activities for encourage participants to communicate and interact effectively with others.

ANNE: I like working through play. Sometimes I look for a different play or game exactly to create this interaction. They like and have a lot of fun. (HPE professional, age 34, P1)

SUSAN: When we had messages, it was really nice. They had to bring a message to read at loud. They brought beautiful things. When someone finished 
the reading, we made comments on what was read. (HPE professional, age 32, P3)

These strategies enabled the adults and older people to perceive social interaction as a result of their participation in community-based programmes and as a contribution to health development.

RESEARCHER: What changes did you perceive in your life after participation in the programme?

DIANA: Increased health. I think health enhancement is all this together, the friends that we make at the health gym and conversations we have about our problems. We talk and laugh... (Participant, age 64, P2)

Diana's response suggest that the aspiration of HPE professionals' pedagogies was likely to be achieved, that is, participants being able to experience and perceive health development in the physical, mental and social dimensions and that they experienced a better quality of life.

In the cognitive dimension, the HPE professionals offered specific activities and worked collaboratively with other health workers in the provision of short talks and counselling on health-related topics.

ANNE: I split the session into a part of exercise and another of counselling (...) Each month we choose a theme for a speech. We usually give short talks because we take advantage of the group, but they don't like missing their exercise routine. (HPE professional, age 34, P1)

RESEARCHER: What kind of activity besides exercise do you do? 
MARGARET: I don't know how our teacher calls... tasks to exercise our mind, you know? It's really nice because at my age I already have this problem of my mind going on blank. (Participant, age 46, P3)

Hence, the data indicated that participants were intellectually stimulated by HPE professionals during their sessions, which shaped their capacity of comprehensibility (Antonovsky 1987).

In the emotional dimension, the HPE professionals intentionally carried out a practice of encouraging participants to (re)build skills, such as self-esteem. As an example of this, a HPE professional described an activity she used to boost participants' self-perception:

SUSAN: I did an activity that was really nice. There was a box and a person would take the box and open it to see a gift inside. The person opened and it was a mirror. Then, she would look at herself. She could not tell her colleagues what was in the box, but that she had to describe what she was seeing so people could guess what was inside (...) the box affected a lot of people. Because there are many of them with problems of low self-esteem and who don't look at the mirror. (HPE professional, age 32, P3)

The HPE professionals assisted the participants to rebuild self-esteem and deal with problems. Therefore, the participants experienced a more positive self-evaluation on their qualities. A health centre coordinator and a participant perceived that they developed their emotional aspects after attending sessions led by the HPE professionals.

MICHELLE: We notice several people that self-esteem has improved a lot, a lot, a lot. (Health centre's coordinator, age 41, P2) 
VICTORIA: I have already been to other gyms. I participated, but it didn't help me much. It helped in the physical part, right? But in the part of self-esteem, this joy, this thing that involves (...) After I joined the group, I saw that I changed a lot in that part of acceptance. (Participant, age 52, P2)

Once again, it becomes evident that HPE professionals' practices allowed the participants to have experiences that could support them to cope with the demands and challenges in everyday life.

In short, the HPE professionals focused on enabling participants to improve physical health outcomes and to develop cognitive, social and emotional skills, which served as health resources for them seeing their lives as more meaningful, comprehensible and manageable (Antonovsky 1987).

\section{Discussion}

The study addressed the topic of how HPE professionals delivered health-related bodily practices for adults and older people as means of health promotion. From a salutogenic perspective, we focused on the pedagogical practices used by HPE professionals to enable participants to experience and perceive health development in the physical, cognitive, emotional and social dimensions.

Three main practices were identified in HPE professionals' work in health promotion: adopting a holistic view of health, serving as a health resource, and nurturing further health resources. We found that these practices were consistent with a salutogenic orientation (Antonovsky 1979), offering an alternative to biomedical perspectives to health promotion, like weight-centric approaches to physical activity (Mansfield and Rich 2013). Also, the findings align with Ericson et al.'s (2018) study of health resources perceived by older women in relation to physical activity. Our findings 
confirmed their results regarding the different origins a health resource can have, that is, physical, cognitive, emotional and social.

The first theme 'adopting a holistic view of health' showed that the HPE professionals focused not only on the physical dimension of participants, but also on their emotions, interests, backgrounds, experiences, psychological needs and living conditions. Working with the complexity and other aspects of the person rather than focusing on particular diseases or risks was one among other points made by Antonovsky $(1987,1996)$ as the core of salutogenesis. The HPE professionals' work was based on holism, which is a key principle of health promotion that acknowledges the interdependence among physical, physiological, psychological, social and spiritual aspects of an individual's life (McEvoy and Duffy 2008). The holistic understanding directed the HPE professionals' work not only at improving physical health outcomes, but also at developing emotional, cognitive and social skills of participants. This finding connects with previous research on the relevance of psychological, environmental and social determinants to adults and older people engagement in a physically active life (Pettigrew et al. 2019; Dicky et al. 2017).

Moreover, the holistic view of health adopted by the HPE professionals provided support for the development of caring relationships with participants. The HPE professionals' practice of listening to them was relevant for identifying their health needs and fostering their motivation to persist in health-related bodily practices. Listening, reflecting and responding to the needs expressed of those cared-for are essential for establishing and maintaining relations of care (Noddings 2012). In turn, building relationships of trust among individuals within an educational context is a key feature of critical pedagogies (Fitzpatrick and Russel 2015). Accordingly, previous studies pointed out that a lack of awareness and empathy between instructors and older 
adults' needs was a barrier for their adherence to programmes (Pettigrew 2019; Dicky et al. 2017).

The second theme generated by this study 'serving as a health resource' was related to the HPE professionals meeting the psychological needs of participants. Using the lens of salutogenesis, the findings suggest that the HPE professionals served as health resource in themselves and in their caring behaviour with the participants. Previous studies (Ericson et al. 2018; Saito, Kai and Takizawa 2012) also demonstrated that social support in caring relationships was meaningful to adults and older people, and enabled them to develop coping strategies, which fostered their capacity to handle problems in everyday life. Adding to the health resources identified by Ericson and colleagues (2018), our results indicated that the HPE professionals' supportive and attentive behaviour also functioned as a resource for participants to add meaningfulness and manageability to their lives (Antonovsky 1979).

The third theme generated in the study 'nurturing further health resources' indicated that the HPE professionals stimulated the development of the social, cognitive and emotional skills, in addition to physical health outcomes of participants. Thus, the findings showed that more than offering opportunities to be physically active, the HPE professionals enabled the participants to experience socialisation as well as cognitive and emotional learning. For instance, they designed activities to address some challenges the participants had to cope with, such as low self-esteem. As a result, the participants perceived a greater sense of control of their emotions and lives. This theme is consistent with Ericson et al. (2018) results on older women's perceived health resources, in terms of social relations, positive energy, self-worth, habit of exercising, and capability in and about physical activity. In addition to their results, our study demonstrated that the provision of education on health-related topics and cognitive 
activities also functioned as resources that guarded against mental decline and added comprehensibility, meaningfulness and manageability to adults and older people's lives. This finding connects with previous research that indicated the need of educational actions in order to provide health-related knowledge and support older adults to make healthy choices in daily life (Pettigrew et al. 2019; Rai et al. 2019; Dicky et al. 2017).

Furthermore, our study indicated the importance of social interaction for adults and older people to continue engaged in a physically active life, as also reported by recent studies (Pettigrew et al. 2019; Bennett et al. 2018). Additionally, our study supported Pettigrew et al.'s (2019) finding that, largely, the social aspect was an outstanding health benefit for adults and older people. An increased sense of belonging and opportunities for making new friends helped them to find meaning in life.

The findings showed that the HPE professionals employed strategies of organising recreational events, focusing on communication skills and diversification of activities as a means of encouraging interaction among participants, which served as a health resource for them. Offering a variety of activities was appealing to the participants as it induced fun and socialisation, which aligns with other studies that indicated that a lack of variation and dynamics in the delivery of activities for older adults tend to hinder them from experiencing pleasure and enjoyment (Pettigrew et al. 2019; Rai et al. 2019).

Although the findings suggest that the HPE professionals were successful in their practice, it is worth noting that they faced problems in developing their approaches. For example, they had a limited capacity of attendance in the communitybased programmes, like in programme 3 where there was a waiting list of people willing to register. Another problem was related to assessment, as they did not develop structured ways of monitoring participants' outcomes, which the HPE professionals and 
their coordinators believed to be important to demonstrate effectiveness of the government-sponsored programmes.

Notwithstanding, the findings supported the pedagogical dimension of HPE professionals' work with adults and older people as part of a process of health promotion. Their practices can be viewed as pedagogical in the sense they focused on instructional behaviours based on caring for participants. Moreover, they were aligned with the subject matter of health-related bodily practices and the health needs of adults and older people. These pedagogical practices are connected with what Kirk (2020) called 'pedagogies of affect'. Kirk $(2020,105)$ used 'pedagogies' to refer to 'the organization and alignment of curriculum, teaching, learning and assessment in ways that render physical education inclusive, fair, and equitable as an embodied experience for young people, in order to empower them'. And, the author adopted the term 'affect' to refer to the affective domain, including constructs such as motivation, caring, body image, self-esteem, resilience, coping, happiness, among others. Also, the HPE professionals' practices can be considered as salutogenically-oriented since they were consistent with the meanings of salutogenesis (Antonovsky 1979, 1987, 1996; Mittelmark and Bauer 2017). That is, they focused on the origins of health while providing meaningful and enjoyable experiences that helped adults and older people to identify, manage and develop health resources. Thus, their practices supported participants to develop assets and strengths, which they could draw upon to cope with challenging situations and move towards a heathier life.

\section{Conclusion}

The study was designed to investigate the pedagogical practices adopted by HPE professionals to deliver health-related bodily practices for adults and older people in community-based programmes. We identified that the HPE professionals developed 
ways of working that allowed them to move beyond a solely biomedical approach and focus on the salutary factors that enable health promotion. Using the theory of salutogenesis (Antonovsky 1979), the study showed that the HPE professionals focused on the origins of health by adopting a holistic view of participants and nurturing further health resources in the physical, cognitive, emotional and social dimensions of their lives. Moreover, this study led to the key finding that the HPE professionals served as a health resource in their pedagogical practices when they became a key person to satisfy participants' psychological needs and demonstrated a caring behaviour, which helped the adults and older people to cope with life situations and see their lives as meaningful, comprehensible and manageable.

The main idea supported by this investigation was that HPE professionals have a richness of possibilities to contribute effectively to health promotion, and not only to disease prevention. In order to help adults and older people in the process of becoming healthier (Quennerstedt 2019), we need to do more than encourage them to move, we need to construct with them caring relationships and meaningful bodily experiences that might serve as health resources for them to move to the ease side of health continuum, towards life cultivation.

\section{References}

Alves, F. S. and Carvalho, Y. M. 2010. Práticas corporais e grande saúde: Um encontro possível. Movimento, Porto Alegre, v. 16, n. 4, p. 229-244.

Antonovsky, Aaron. 1979. Health, Stress and Coping. London: Jossey-Bass. Antonovsky, Aaron. 1987. Unravelling the Mystery of Health: How People Manage Stress and Stay Well. San Francisco: Jossey-Bass Publishers. 
Antonovsky, Aaron. 1996. "The Salutogenic Model as a Theory to Guide Health Promotion." Health Promotion International 11 (1): 11-18.

Armour, K. and Harris, J. 2013. "Making the Case for Developing New PE-for-Health Pedagogies.” Quest 65 (2): 201-19. doi:10.1080/00336297.2013.773531.

Bennett, E. V., Clarke, L. H., Wolf, S. A., Dunlop, W. L., Harden, S. M., Liu, Y., ... \& Beauchamp, M. R. (2018). Older adults' experiences of group-based physical activity: A qualitative study from the 'GOAL' randomized controlled trial. Psychology of Sport and Exercise, 39, 184-192.

Brazil. Ministry of Health. 2008. "Portaria No 154, de 24 de Janeiro de 2008. Cria Os Núcleos de Apoio à Saúde Da Família - NASF.” Diário Oficial Da União, Brasília, DF 43 (Seção 1). Brasília: D.O.U. nº 43, de 04/03/2008, Seção 1: fls.38-42.

Brazil. Ministry of Health. 2011. "Portaria N $N^{0} 719$, de 7 de Abril de 2011. Institui o Programa Academia da Saúde no âmbito do Sistema Único de Saúde.” Diário Oficial Da União, Brasília, DF, 5-7.

Brazil. Ministry of Health. 2013. Glossário Temático: promoção da saúde. Brasília: Ministério da Saúde.

Brazil. Ministery of Health. 2014. Política Nacional de Promoção Da Saúde: PNPS: Revisão Da Portaria MS/GM No 687, de 30 de Março de 2006. [National Health Promotion Policy: PNPS/Brazil: Revision of the MS/GM Ordinance $N^{\circ}$ 687, March 30th, 2006]. 2.ed.rev. Brasília: Ministério da Saúde.

Charmaz, Kathy. 2006. Constructing Grounded Theory: A Practical Guide through Qualitative Analysis. Book. Vol. 10. London: Sage Publications.

Ericson, H., Quennerstedt M., Skoog T., and Johansson, M. 2018. "Health Resources, 
Ageing and Physical Activity: A Study of Physically Active Women Aged 69-75

Years." Qualitative Research in Sport, Exercise and Health 10 (2). Routledge: 206-22. doi:10.1080/2159676X.2017.1393453.

Fitzpatrick, K. and Russell, D. 2015. “On Being Critical in Health and Physical Education." Physical Education and Sport Pedagogy 20 (2). Routledge: 159-73. doi:10.1080/17408989.2013.837436.

Glaser, B. G., \& Strauss, A. L. 2017. Discovery of grounded theory: Strategies for qualitative research. London: Routledge.

Grant, Bevan. 2012. “'Against the Grain”: Over 75 Years and Joining a Community Exercise Programme." Qualitative Research in Sport, Exercise and Health 4 (1): 1-14. doi:10.1080/2159676X.2011.653541.

Haerens, Leen, Greet Cardon, Ilse De Bourdeaudhuij, and David Kirk. 2011. "Toward the Development of a Pedagogical Model for Health-Based Physical Education." Quest 63 (3): 321-38. doi:10.1080/00336297.2011.10483684.

Jette, Shannon, and Patricia Vertinsky. 2011. "Exercise Is Medicine: Understanding the Exercise Beliefs and Practices of Older Chinese Women Immigrants in British Columbia, Canada." Journal of Aging Studies 25 (3): 272-84. doi:10.1016/j.jaging.2010.10.001.

Kirk, David. 2006. "The 'obesity Crisis' and School Physical Education.” Sport, Education and Society 11 (2): 121-33. doi:10.1080/13573320600640660.

Kirk, David. 2013. Educational Value and Models-Based Practice in Physical Education. Educational Philosophy and Theory 45(9), 973-986.

Kirk, David. 2020. Precarity, Critical Pedagogy and Physical Education. London: Routledge. 
Kolb, S. M. 2012. Grounded theory and the constant comparative method: Valid research strategies for educators. Journal of emerging trends in educational research and policy studies, 3(1), 83-86.

Lee, I-Min, Eric J Shiroma, Felipe Lobelo, Pekka Puska, Steven N Blair, Peter T Katzmarzyk, and S N Blair. 2012. "Impact of Physical Inactivity on the World's Major Non-Communicable Diseases.” Lancet 380 (9838): 219-29. doi:10.1016/S01406736(12)61031-9.

Lyon, Alexander T.C., Ross D. Neville, and Kathleen M. Armour. 2017. "The Role of Fitness Professionals in Public Health: A Review of the Literature." Quest 69 (3). Routledge: 313-30. doi:10.1080/00336297.2016.1224193.

Mansfield, L. and Rich, E. 2013. "Public Health Pedagogy, Border Crossings and Physical Activity at Every Size.” Critical Public Health 23 (3): 356-70. doi:10.1080/09581596.2013.783685.

McCuaig, Louise, and Mikael Quennerstedt. 2018. "Health by Stealth - Exploring the Sociocultural Dimensions of Salutogenesis for Sport, Health and Physical Education Research." Sport, Education and Society 23 (2): 111-22. doi:10.1080/13573322.2016.1151779.

McCuaig, Louise, Mikael Quennerstedt, and Doune Macdonald. 2013. “A Salutogenic, Strengths-Based Approach as a Theory to Guide Hpe Curriculum Change." Asia-Pacific Journal of Health, Sport and Physical Education 4 (2): 109-25. doi:10.1080/18377122.2013.801105.

McEvoy, Liz, and Anita Duffy. 2008. "Holistic Practice - A Concept Analysis." Nurse Education in Practice 8 (6). Churchill Livingstone: 412-19.

Mittelmark, Maurice B. and Bauer, Georg F. 2017. "The Meanings of Salutogenesis.” 
In The Handbook of Salutogenesis, edited by Maurice B. Shifra Sagy Mittelmark, Monica Eriksson, Georg F. Bauer, Jürgen Pelikan, Bengt Lindström, and Geir Arild Espnes, 7-14. Springer.

Noddings, Nel. 2012. "The Caring Relation in Teaching." Oxford Review of Education 38 (6): 771-81.

Pettigrew, S., Burton, E., Farrier, K., Hill, A. M., Bainbridge, L., Airey, P., Lewins, G. \& Hill, K. D. (2019). Encouraging older people to engage in resistance training: A multi-stakeholder perspective. Ageing \& Society, 39(8), 1806-1825.

Piggin, J. (2019) The politics of physical activity. New York: Routledge, 134 p.

Pühse, Uwe, D Barker, W.-D. Brettschneider, A K Feldmeth, E Gerlach, L McCuaig, Thomas L McKenzie, and M Gerber. 2011. "International Approaches to HealthOriented Physical Education: Local Health Debates and Differing Conceptions of Health.” International Journal of Physical Education 48 (3): 4-17.

Quennerstedt, Mikael. 2008. "Exploring the Relation between Physical Activity and Health - A Salutogenic Approach to Physical Education.” Sport, Education and Society 13 (3): 267-83. doi:10.1080/13573320802200594.

Quennerstedt, Mikael. 2019. "Healthying Physical Education - on the Possibility of Learning Health.” Physical Education and Sport Pedagogy 24 (1): 1-15. doi:10.1080/17408989.2018.1539705.

Rai, R., Jongenelis, M. I., Jackson, B., Newton, R. U., \& Pettigrew, S. (2019). Factors influencing physical activity participation among older people with low activity levels. Ageing \& Society, 1-21.

Sallis, R. E. 2009. “Exercise Is Medicine and Physicians Need to Prescribe It!” British Journal of Sports Medicine 43 (1): 3-4. doi:10.1136/bjsm.2008.054825. 
Stenhouse, Lawrence. 1978. "Case Study and Case Records : Towards a Contemporary History of Education.” British Educational Research Journal 4 (2): 21-39.

Taylor, Denise. 2014. "Physical Activity Is Medicine for Older Adults.” Postgraduate Medical Journal 90: 26-32. doi:10.1136/postgradmedj-2012-131366.

Van Dyck, D., Mertens, L., Cardon, G., De Cocker, K., \& De Bourdeaudhuij, I. (2017). Opinions Toward Physical Activity, Sedentary Behavior, and Interventions to Stimulate Active Living During Early Retirement: A Qualitative Study in Recently Retired Adults, Journal of Aging and Physical Activity, 25(2), 277-286. 